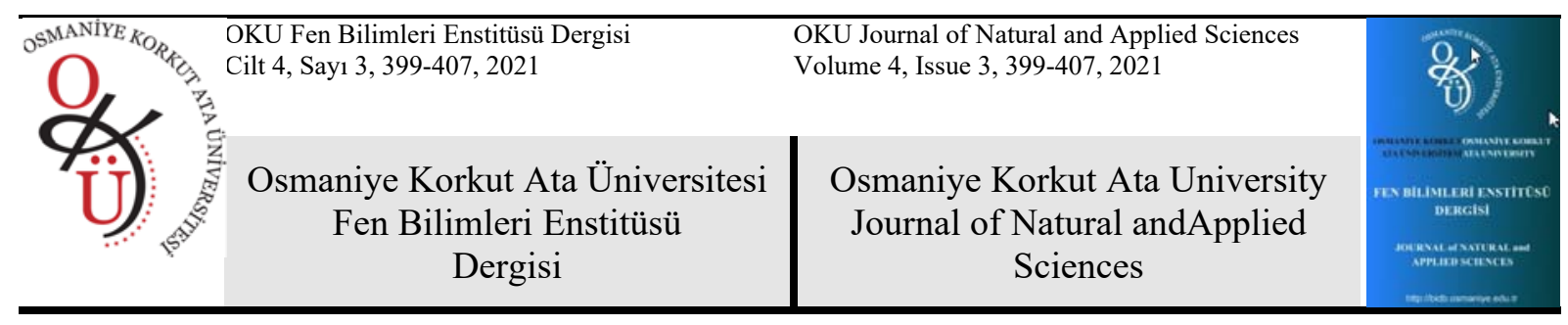

\title{
Karayolları Enerji Tüketiminin Motorlu Taşıt Türlerine ve Kullanılan Akaryakıt Miktarına Göre Modellenmesi
}

\author{
Ömer Faruk CANSIZ ${ }^{1}$, İbrahim ERGINER ${ }^{2 *}$, Fatih ERIȘEN ${ }^{3}$ \\ 1,2,3̇̇skenderun Teknik Üniversitesi, Mühendislik ve Doğa Bilimleri Fakültesi, İnşaat Mühendisliği Bölümü, 31200, Hatay
}

${ }^{1}$ https://orcid.org/0000-0001-6857-2513

${ }^{2} \mathrm{https}: / /$ orcid.org/0000-0002-6001-3124

${ }^{3} \mathrm{https}: / /$ orcid.org/0000-0002-2750-6138

*Sorumlu yazar: ibrahim.erginer.mfbe18@iste.edu.tr

\section{Araştırma Makalesi}

\section{Makale Tarihçesi:}

Geliş tarihi: 21.01 .2021

Kabul tarihi:26.07.2021

Online Yayınlanma: 15.12.2021

\section{Anahtar Kelimeler:}

Karayollarında enerji tüketimi

Yapay sinir ağları

Çok değişkenli regresyon

\section{ÖZET}

Karayollarında tüketilen enerji kaynağını fosil yakıtlardan almaktadır. Fosil yakıtlar yenilenemeyen enerji kaynakları arasında yer almakta ve nüfus, tarım, sanayi ve hizmet sektörlerindeki büyümeler bu kaynakların tüketimini artırmaktadır. Bu çalışmada, Türkiye'de karayollarındaki enerji tüketiminin araç türleri ve toplam tüketilen akaryakıt miktarları arasındaki ilişki incelenmiştir. Enerji tüketiminin tahmini için yapay sinir ağları (YSA) ve çok değişkenli regresyon (MR) yöntemleri ile modellemeler yapılmıştır. Oluşturulan modelde, trafiğe kayıtlı otomobil ve motosiklet sayıları, diğer motorlu taşıt türleri ve toplam tüketilen akaryakıt miktarı bağımsız değişken olarak incelenmiştir. Oluşturulan modelin değerlendirilmesinde determinasyon katsayısı $\left(\mathrm{R}^{2}\right)$, hataların karelerinin ortalaması (HKO), korelasyon katsayısı $(\mathrm{R})$ ve ortalama yüzde hata $(\mathrm{OYH})$ değerleri performans kriteri olarak dikkate alınmıştır. Dikkate alınan kriterlere göre en iyi modelin YSA modeli olduğu gözlemlenmiştir. Bu modelde $\mathrm{R}^{2}$ değeri 0,998; HKO değeri 37106,774; R değeri 0,999 ve OYH değeri -0,13olarakhesaplanmıştır. Oluşturulan model ile karayollarında enerji tüketimi başarılı bir şekilde tahmin edilmiştir.

\section{Modeling Highways Energy Consumption According to Motor Vehicle Types and the Amount of Fuel Used}

\section{Research Article}

\section{ArticleHistory:}

Received: 21.01.2021

Accepted: 26.07 .2021

Published online: 15.12.2021

\section{Keywords:}

Energy consumption on highways Artificial neural network

Multivariate regression

\begin{abstract}
The energy source consumed on highways is derived from fosil fuels. Fossil fuels are among then non-renewable energy sources and growth in the population, agriculture, industry and service sectors in creases the consumption of the seresources. In this study, energy consumption is studied the relationship between vehicle type sand total amount of fuel consumed in energy consumption highways in Turkey. For the estimation of energy consumption, modeling has been made with artificial neural networks (ANN) and multivariate regression (MR) methods. In the model created, the number of automobiles and motorcycles registered in the traffic, other types of motor vehicles and the total amount of fuel consumed were examined as independent variables. In the evaluation of the created model, coefficient of determination $\left(\mathrm{R}^{2}\right)$, mean squares of errors (MSE) and mean percent error (MPE) values were considered as performance criteria. It was observed that the best model according to the criteria considered was ANN. In this model the $\mathrm{R}^{2}$ value was calculated as 0,998 ; the MSE value as 37106,774 ; the $\mathrm{R}$ value as 0,999 ; and the MPE value as $-0,13$. Energy
\end{abstract}


consumption on highways has been successfully estimated with the created model.

To Cite: Cansız ÖF., Erginer İ., Erişen F. Karayolları Enerji Tüketiminin Motorlu Taşıt Türlerine ve Kullanılan Akaryakıt Miktarına Göre Modellenmesi. Osmaniye Korkut Ata Üniversitesi Fen Bilimleri Enstitüsü Dergisi 2021; 4(3): 399-407.

\section{Giriş}

Fiziksel anlamda iş yapabilme yeteneği olarak tanımlanan enerji; başta insan yaşamı olmak üzere sanayi, tarım, hizmet sektörleri ve ulaşımın temel ögesidir.

Dünya nüfusunun zamanla artması ve gelişmekte olan ülkelerin yaşam standartlarının gelişmesiyle son yıllarda dünya üzerindeki toplam enerji üretimi de önemli miktarda artmıştır. Geçtiğimiz 50 yıl içerisinde birincil enerji üretiminde 4 kat, sıvı yakıtların üretiminde ise 5,4 kat artış olduğu gözlemlenmiştir (Soruşbay, 2007).

Doğal kaynakların sınırlı oluşu ve artan enerji talebi dikkate alındığında, ulaştırmada enerji tüketiminin analizi ve tüketimle ilgili emisyon azaltılmasının incelenmesi önemli bir konu olmuştur (Chaive ark., 2016).

Nüfus ve sanayileşmedeki artışa paralel olarak Türkiye'de enerji tüketimi, özellikle 1980'den sonra hızla artmaya başlamıştır. İhracata dayalı dışa açık birikim modelinin uygulandığı bu süreçte önemini kaybeden tarım sektörünün yerine sanayi ve hizmetler sektörü ön plana çıkmaya başlamıştır. Ekonominin genel yapısında yaşanan bu değişim daha fazla enerji kullanımını gerektirdiğinden dolayı özellikle petrol, doğal gaz ve kömür türü fosil yakıtlara olan taleplerde artış gerçekleşmiştir (Mucuk ve Uysal, 2009).

Türkiye'de2017 y1lında toplam enerji tüketimi 145,3 Mtep (milyon ton eşdeğer petrol) olmuştur. Türkiye'nin toplam enerji tüketimi 1990 yılına göre \%177, 2005 yılına göre \%64, 2016 yılına göre ise \%6,7 oranında artmıştır. Yine Türkiye'de 2017 yılında toplam enerji tüketiminin dağılımına bakıldığında, en yüksek tüketimin \%24,8 ile mesken ve hizmetler ve $\% 24,4$ ile sanayi sektöründe gerçekleştiği görülmektedir. Bunu \%23,1 ile enerji ve çevrim sektörü, \%19,6 ile ulaştırma, \%5,1 ile enerji dışı ve \%2,9 ile tarım ve hayvancılık sektörü takip etmektedir(Enerji ve Tabii Kaynaklar Bakanlığ 1$)$.

Ülkemizde 2017 y1lı itibariyle ulaştırma kaynaklı enerji tüketim oranının \%19,6olması bu konuda yapılacak çalışmalarla enerji verimliliğinin artırılması ihtiyacının ne kadar önemli olduğunun bir göstergesidir. Ayrıca ülkemizdeki motorlu kara taşıtları sayısı 1999 yılında 7.758 .511 iken 2019 yılı itibariyle 23.156.975değerine ulaşarak yaklaşık \%198 oranında bir artış gerçekleştiği görülmektedir (TUIK). Bu artışa paralel olarak karayollarında enerji tüketimi de artış göstermiş ve enerji verimliliği gün geçtikçe daha fazla önem kazanmaya başlamıştır.

Enerji Verimliliği Vakfı, enerji verimliliğini “Enerji maliyetlerinin yükünün azaltılması, enerjide arz güvenliğinin sağlanması, dışa bağımlılıktan kaynaklanan risklerin asgariye indirilmesi, düşük karbonlu ekonomiye geçiş ve çevrenin korunması, yerli enerji potansiyelinin azami verimlilikte değerlendirilerek sürdürülebilirliğinin sağlanması gibi ulusal stratejik hedefleri tamamlayan ve bunları yatay kesen disiplinler arası stratejik bir faaliyetler bütünüdür” şeklinde tanımlamıştır (Enerji Verimliliği Derneği). 
$\mathrm{Bu}$ çalışmada enerji verimliliğine katkı sağlaması amacıyla 2004-2018 yılları arasındaki toplam otomobil ve motosiklet sayısı, bu iki tür dışında kalan motorlu kara taşıtı sayısı ve karayollarında tüketilen toplam akaryakıt miktarına göre enerji tüketimi tahmin edilmiştir. Tahmin modelleri, yapay zekâ tekniklerinden YSA ve istatistiksel metotlardan MR yöntemleri kullanılarak oluşturulmuştur.

\section{Materyal ve Metot}

Bu çalışmada, karayollarında tüketilen enerji miktarının tahmini için modeller oluşturulmuştur. Tahmin modellerinin oluşturulması için YSA ve çok değişkenli regresyon yöntemlerinden yararlanılmıştır.

Modeller oluşturulurken 2004-2018 yılları arasında kullanım amacına göre daha çok özel kullanıma hizmet eden otomobil ve motosiklet sayılarının toplamı,diğer motorlu kara taşıtlarının toplam sayıları ve karayollarında tüketilen toplam akaryakıt miktarı bağımsız değişken olarak kullanılmıştır. Karayollarında tüketilen toplam enerji miktarı ise bağımlı değişken olarak kullanılmış ve bir veri seti oluşturulmuştur. Oluşturulan veri seti ile MatLab2015b programı kullanılarak regresyon analizleri ve YSA analizleri yapılmıştır. Verilerin \%66,7'si eğitim, \%33,3'ü test için kullanılmıştır. 2004 yılından başlayarak iki yıl eğitim bir yıl test verisi olacak şekilde devam eden düzenle eğitim ve test verileri oluşturulmuştur. Modellerde kullanılan veri seti Tablo 1'de verilmiştir.

Tablo 1. Veri Seti Tablosu

\begin{tabular}{lcccc}
\hline Yıllar & $\begin{array}{c}\text { Otomobil + Motosiklet } \\
\text { Sayıları }\end{array}$ & $\begin{array}{c}\text { Diğer Motorlu Kara } \\
\text { Taşıtları Sayları }\end{array}$ & $\begin{array}{c}\text { Tüketilen } \\
\text { Akaryakıt (ton) }\end{array}$ & $\begin{array}{c}\text { Enerji Tüketimi } \\
\text { (btu) }\end{array}$ \\
\hline 2004 & 6619117 & 3617240 & 15240.400 & 11510 \\
2005 & 7213811 & 3932015 & 16199.000 & 11781 \\
2006 & 7963823 & 4263570 & 16937.978 & 12599 \\
2007 & 8475648 & 4547297 & 17890.847 & 13594 \\
2008 & 8978012 & 4787383 & 17913.752 & 12624 \\
2009 & 9397225 & 4919475 & 18206.872 & 12516 \\
2010 & 9934359 & 5161244 & 18461.624 & 13535 \\
2011 & 10640301 & 5449227 & 19348.914 & 15451 \\
2012 & 11306597 & 5726816 & 20656.990 & 16303 \\
2013 & 12006749 & 5932698 & 21746.587 & 17677 \\
2014 & 12686381 & 6142340 & 22557.586 & 18497 \\
2015 & 13527701 & 6466771 & 25740.274 & 21525 \\
2016 & 14321731 & 6768693 & 27848.652 & 23478 \\
2017 & 15138778 & 7080167 & 30565.439 & 24731 \\
2018 & 15609518 & 7256403 & 33712.271 & 24795 \\
\hline
\end{tabular}

\section{Çok Değişkenli Regresyon Yöntemi}

Oluşturulan modelde birden fazla bağımsız değişken olduğundan çok değişkenli regresyon modelleri kullanılmıştır. Çok değişkenli regresyonla bağımsız değişkenler ile bağımlı değişkenler arasındaki ilişki denklemlerle ifade edilmektedir. Bu çalışmada lineer, interaction, quadraticve pure-quadratic regresyon yöntemleri kullanılmıştır. Bu yöntemlerin genel denklemi sırasıyla Denklem1, Denklem2, Denklem3 ve Denklem4'te verilmiştir.

$$
y=\beta_{0}+\beta_{1} \cdot x_{1}+\beta_{2} \cdot x_{2}+\beta_{3} \cdot x_{3}
$$




$$
\begin{aligned}
y= & \beta_{0}+\beta_{1} \cdot x_{1}+\beta_{2} \cdot x_{2}+\beta_{3} \cdot x_{3}+\beta_{4} \cdot x_{1} \cdot x_{2} \\
& +\beta_{5} \cdot x_{1} \cdot x_{3}+\beta_{6} \cdot x_{2} \cdot x_{3} \\
y= & \beta_{0}+\beta_{1} \cdot x_{1}+\beta_{2} \cdot x_{2}+\beta_{3} \cdot x_{3}+\beta_{4} \cdot x_{1} \cdot x_{2} \\
& +\beta_{5} \cdot x_{1} \cdot x_{3}+\beta_{6} \cdot x_{2} \cdot x_{3}+\beta_{7} \cdot x_{1}{ }^{2}+\beta_{8} \cdot x_{2}{ }^{2} \\
& +\beta_{9} \cdot x_{3}{ }^{2} \\
y= & \beta_{0}+\beta_{1} \cdot x_{1}+\beta_{2} \cdot x_{2}+\beta_{3} \cdot x_{3}+\beta_{4} \cdot x_{1}{ }^{2} \\
& +\beta_{5} \cdot x_{2}{ }^{2}+\beta_{6} \cdot x_{3}{ }^{2}
\end{aligned}
$$

Bu denklemlerde " $x_{i}$ " değerleri bağımsız değişkenler olan otomobil + motosiklet sayıları, diğer motorlu kara taşıtları sayıları, kara yollarında tüketilen toplam akaryakıt miktarlarını, " $y$ "değeri karayollarında tüketilen toplam enerji miktarını ve " $\beta_{i}$ " değerleri ise regresyon katsayısını temsil etmektedir.

\section{Yapay Sinir Ağları Yöntemi}

Günümüzde yapay zekâ teknikleri basit matematiksel denklemleri çözmekten, bir görüntüdeki nesneyi tanımlamaya hatta bir röntgen filminden kişinin herhangi bir hastalığa sahip olup olmadığını belirlemeye kadar pek çok alanda kullanılmaktadır. Bir yapay zekâ tekniği olan YSA, insan öğrenmesini taklit ederek genellemeler yapma ve eldeki verilerden çıkarımlar yapmayı sağlayan bilgisayar temelli bir yöntemdir (Öztürk ve Şahin, 2018).

Yapılan bir çalışma, yapay sinir ağları tekniklerinin elektrik enerjisi tüketiminin tahmininde, ortalama mutlak yüzde hata ve mutlak yüzde hata kriterlerine göre Box-Jenkins modelleri ve regresyon tekniğine kıyasla daha iyi bir tahmin aracı olduğunu göstermiştir (Hamzaçebi ve Kutay, 2004).

Çetinkaya ve Acarman(2020) yaptıkları bir çalışmada araç üzerinde bulunan kamera algılayıcısı ile çekilen trafik sahne resimleri üzerinde trafik işaret levhası tespiti için yapay zeka tekniklerini kullanarak verimli bir yöntem önermişlerdir.

Yapılan bir araştırmada bir yapay zeka tekniği olan Derin Öğrenme tabanlı model eğitimi ve otonom sürüş testleri sürüş simülatöründe gerçekleştirmiştir.Çalışmada sürüş simülatöründe gerçekleştirilen testler sonucunda PID (Proportional Integral Derivative) kontrol tabanlı sürüşte de başarılı sonuçlar elde edilmiş olmasına rağmen, Derin Öğrenme tabanlı modelin performansının daha iyi olduğu belirtilmiştir (Koray ve Dirik, 2020).

Yapılan bir çalışmada araçları tespit etmek ve yedi sınıfa ayırmak için görüş sistemlerinde derin bir evrişimli sinir ağı önerilmiş ve yedi araç sınıfı için \%89 ile \%99 arasında ortalama hatırlama oranları elde edilmiştir (Adu-Gyamfi ve ark., 2017).

YSA'da sinir sistemindeki gibi nöronlar bulunmaktadır. Nöronlar birleşerek bir ağ oluştururlar ve YSA'da herhangi bir ön kabul yapılmadan deneme-yanılma yöntemiyle öğrenme gerçekleştirilmektedir. Öğrenme gerçekleşirken bağımsız değişkenler değerlendirilerek bağımlı değişkenlerin tahmini yapılmaktadır. Şekil 1'de YSA' da bir nöronun nasıl çalıştığı gösterilmiştir (Erginer ve ark., 2020). 




Şekil 1. YSA Nöron Mekanizmas1

Şekil 1'de gösterilen nöron mekanizmasında " $x$ " değişkeni girdileri, "w” değişkeni ağırlıkları, " $f$ " transfer fonksiyonunu "b" bias değerini ve y ise nöronun çıktısını ifade etmektedir. Bu mekanizmada her bir girdi ağırlıklarla çarpıldıktan sonra, sonuçların toplamları alınmakta ve bias değerleri eklenmektedir. $\mathrm{Bu}$ değerin transfer fonksiyonundan geçirilmesiyle elde edilen sonuç nöronun çıktısı olmaktadır(Erginer ve ark., 2020). Şekil 1'de verilen mekanizmanın denkleme dönüştürülmüş hali Denklem 5'te görülmektedir.

$$
y=f\left(\sum_{i=1}^{N} x_{i} \cdot w_{i}+\operatorname{bias}_{i}\right)
$$

Bu çalışmada en iyi model Levenberg-Marquardt eğitim algoritması ve tanjant sigmoid (tansig) transfer fonksiyonu ile oluşturulmuştur. Tansig transfer fonksiyonunun formülasyonu Denklem 6 'da görülmektedir.

$$
\operatorname{Tansig}(N)=\frac{2}{\left(1+\exp ^{(-2 N)}\right)}-1
$$

\section{Bulgular ve Tartışma}

Otomobil+motosiklet sayıları, diğer motorlu kara taşıtları sayıları, karayollarında tüketilen toplam akaryakıt miktarı bağımsız değişkenleri kullanılarak YSA metodu ile oluşturulan enerji tüketim tahmini modelinin korelasyon grafiği Şekil 2'de, eğitim grafiği ise Şekil 3'te verilmiştir. 

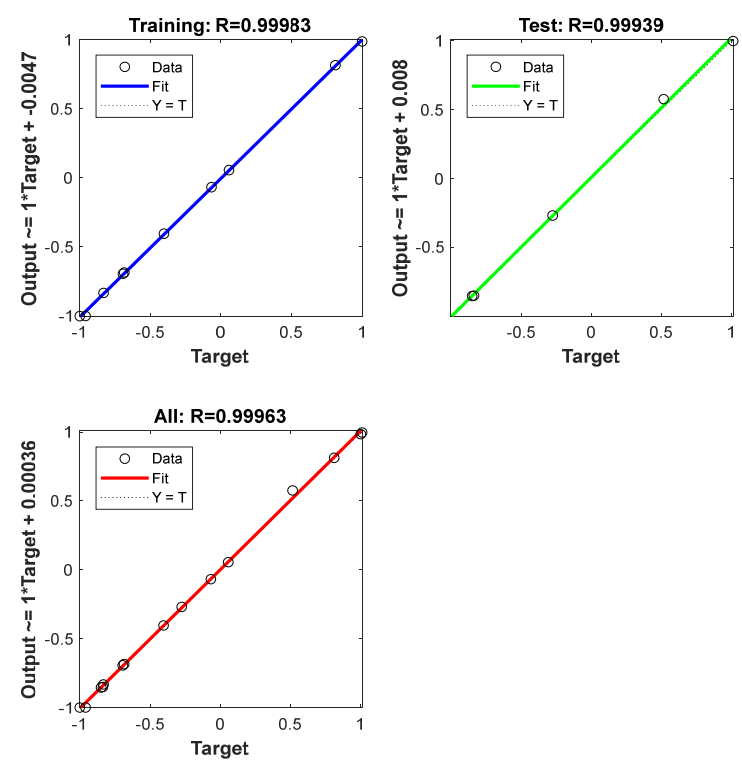

Şekil 2.Enerji tüketim modeli R grafiği

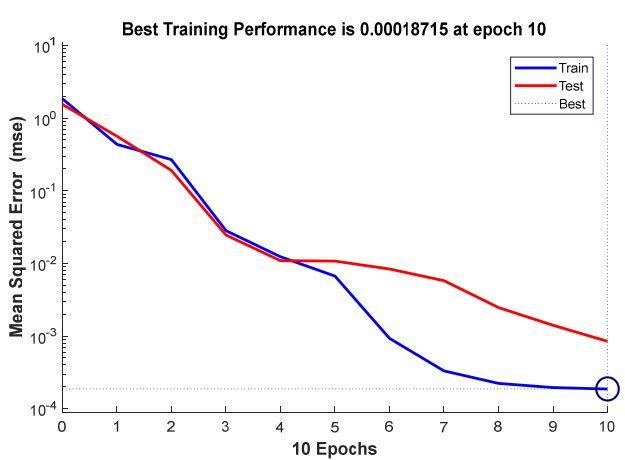

Şekil 3.Enerji tüketim modeli eğitim grafiği

Oluşturulan regresyon modellerinden en iyi sonucu veren pure-quadratic modelin denklemi Denklem 7'de, lineer, interaction ve quadratic modellerin denklemleri ise sirasiyla Denklem 8, 9 ve 10'da verilmiştir.

$$
\begin{aligned}
y= & 1,78 \cdot 10^{4}+1,28 \cdot 10^{-2} \cdot x_{1} \\
& -4,53 \cdot 10^{-2} \cdot x_{2}+3,65 \cdot 10^{-3} \cdot x_{3} \\
& \quad-6,75 \cdot 10^{-10} \cdot x_{1}{ }^{2}+4,45 \cdot 10^{-6} \cdot x_{2}{ }^{2} \\
& -4,89 \cdot 10^{-11} \cdot x_{3}{ }^{2} \\
y= & 4187,86+0,00288 \cdot x_{1} \\
& -0,005725 \cdot x_{2}+0,00058468 \cdot x_{3} \\
y= & 29900,45+0,007041 \cdot x_{1} \\
& -0,034183 \cdot x_{2}+0,001863 \cdot x_{3} \\
& +1,186 \cdot 10^{-9} \cdot x_{1} \cdot x_{2} \\
& -9,106 \cdot 10^{-10} \cdot x_{1} \cdot x_{3} \\
& +1,699 \cdot 10^{-9} \cdot x_{2} \cdot x_{3} \\
y= & -62039,146+0,06502 \cdot x_{1} \\
& -0,22238 \cdot x_{2+} 0,03174 \cdot x_{3} \\
& -9,19 \cdot 10^{-8} \cdot x_{1} \cdot x_{2} \\
& +6,16 \cdot 10^{-9} \cdot x_{1} \cdot x_{3} \\
& -1,91 \cdot 10^{-8} \cdot x_{2} \cdot x_{3} \\
& +1,44 \cdot 10^{-8} \cdot x_{1}{ }^{2}+1,46 \cdot 10^{-7} \cdot x_{2}{ }^{2} \\
& +2,14 \cdot 10^{-10} \cdot x_{3}{ }^{2}
\end{aligned}
$$


Denklemlerde $x_{1}, x_{2}, x_{3}$ değişkenleri sırasıyla otomobil+motosiklet sayıları, diğer motorlu kara taşıtları sayısı ve karayollarında tüketilen toplam akaryakıt miktarlarını ifade etmektedir.

Çok değişkenli regresyon ve YSA modellerinin kıyaslanması ait HKO, OYH, R ve $\mathrm{R}^{2}$ değerleri Tablo 2'de verilmiştir.

Tablo 2. YSA ve regresyon modellerinin kiyaslanmas1

\begin{tabular}{lcccc}
\hline & OYH & $\mathbf{R}^{\mathbf{2}}$ & HKO & $\mathbf{R}$ \\
\hline Lineer & 0,965954 & 0,96595 & 1603457 & 0,982 \\
Interaction & $-1,36404$ & 0,98761 & 406643 & 0,993 \\
Quadratic & $-6,51691$ & 0,97007 & 7635112 & 0,984 \\
$\begin{array}{l}\text { Pure- } \\
\text { quadratic }\end{array}$ & $-3,13446$ & 0,99296 & 543707 & 0,996 \\
YSA & $-0,13235$ & 0,99878 & 37106 & 0,999 \\
\hline
\end{tabular}

Tablo 2'deki verilere göre YSA modeli, çok değişkenli regresyon modellerine göre daha başarılı sonuçlar vermiştir. Oluşturulan YSA modelinin R değeri olan 0,999 regresyon modellerine göre 1'e daha yakındır. Modellerde genel olarak iyi korelasyon değerlerine ulaşılmıştır. Ayrıca YSA modelinin HKO ve OYH değerleri sirasıyla 37,106 ve -0,132 olup bu değerlerin de regresyon modellerine göre daha düşük olduğu gözlemlenmiştir. Bu da YSA modelinin istatistiksel modellere göre daha başarılı sonuçlar verdiğini göstermektedir(Cansız ve ark., 2020).

YSA enerji tüketim modeli ile elde edilen enerji tüketimi tahmin değerlerinin gerçek enerji tüketim değerleriyle karşılaştırılması Şekil 4’te gösterilmiştir.

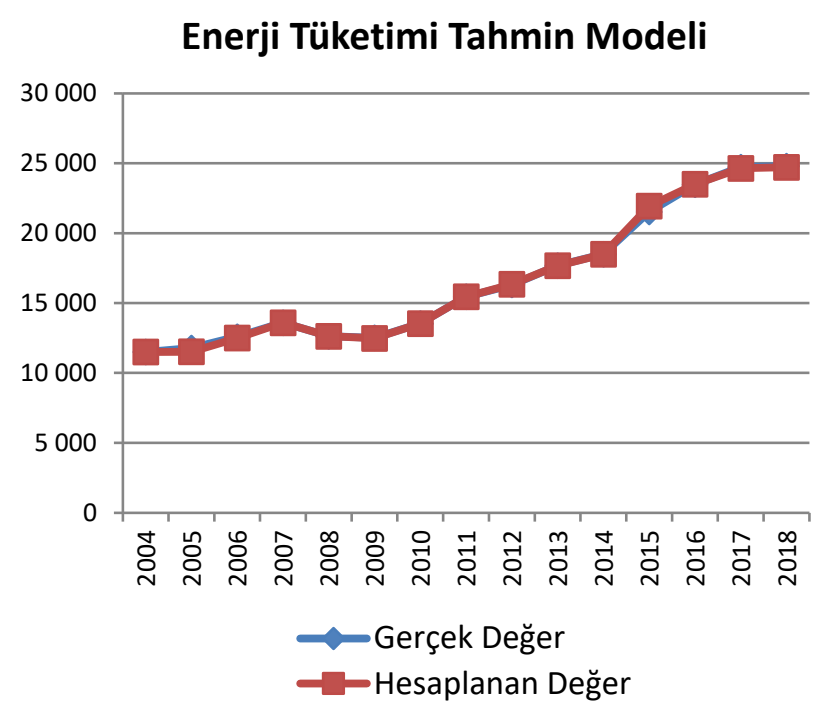

Şekil 4.Enerji tüketim tahmininin gerçek değerle karşılaştırılması

Şekil 4'te görüldüğü gibi tahmin sonuçları ile gerçek değerler çok iyi bir uyum içerisinde hareket etmiştir. 2005 ve 2015 yıllarındaki küçük farklar dışında enerji tüketim değerleri, oluşturulan YSA modeli ile başarılı bir şekilde tahmin edilmiştir. 


\section{Sonuçlar}

Yapılan çalışmada karayollarındaki otomobil ve motosiklet toplam sayıları, diğer motorlu kara taşıtları sayıları ve karayollarında tüketilen toplam akaryakıt miktarları kullanılarak karayollarındaki enerji tüketimi tahmin edilmeye çalışılmıştır. Tahmin modelleri YSA ve çok değişkenli regresyon yöntemleri kullanılarak oluşturulmuştur. Oluşturulan enerji tüketimi tahmin modellerine ait $\mathrm{HKO}, \mathrm{OYH}, \mathrm{R}^{2}$ ve R değerleri incelendiğinde en iyi sonuçların YSA modeli ile elde edildiği görülmüştür.

Çok değişkenli regresyon yöntemi ile oluşturulan tahmin modelleri karşılaştırıldığında ise purequadratic regresyon modeli, diğer çok değişkenli regresyon modellerine göre daha iyi sonuçlar vermiştir. Yapılan bu çalışmada elde edilen sonuçlara göre; otomobil ve motosiklet toplam sayıları, diğer motorlu kara taşıtları sayıları ve karayollarında tüketilen toplam akaryakıt miktarları değişkenleri kullanılarak karayollarında enerji tüketimi başarılı bir şekilde tahmin edilmiştir. Ayrıca buna benzer yapılacak çalışmalarda kullanılacak bağımsız değişkenlerin otomobil ve motosiklet toplam sayıları, diğer motorlu kara taşıtları sayıları ve karayollarında tüketilen toplam akaryakıt miktarları kullanılarak geliştirilebileceği önerilmiştir.

\section{Teşekkür}

$\mathrm{Bu}$ çalışmanın yapılması aşamasında, veri setlerinin oluşturulmasında kaynak olarak yararlanılan Enerji ve Tabii Kaynaklar Bakanlığı'na, Türkiye İstatistik Kurumu'na ve Karayolları Genel Müdürlüğü'ne teşekkürlerimizi sunarız.

\section{Çıkar Çatışması Beyanı}

Makale yazarları herhangi bir çıkar çatışması olmadığını beyan eder.

\section{Araştırmacıların Katkı Oranı Beyan Özeti}

Yazarlar makaleye eşit oranında katkı sağlamış olduğunu beyan eder.

\section{Kaynakça}

Adu-Gyamfi YO., Asare SK., Sharma A., Titus T. Automated vehicle recognition with deep convolutional neural networks. Transportation Research Record 2017; 2645(1): 113-122.

Cansız ÖF., Ünsalan K., Erginer İ. Karayolları enerji tüketiminin yapay zeka ve regresyon yöntemleri ile modellenmesi. Uludağ University Journal of The Faculty of Engineering 2020; 25(3): 1297-1314.

Chai J., Lu QY., Wang SY., Lai KK. Analysis of road transportation energy consumption demand in China. Transportation Research Part D: Transport and Environment 2016; 48: 112-124.

Çetinkaya M., Acarman T. Trafik işaret levhası tespiti için derin öğrenme yöntemi. Akı1lı Ulaşım Sistemleri ve Uygulamaları Dergisi 2020; 3(2): 140-157.

Enerji ve Tabii Kaynaklar Bakanlığı, Sektörlere göre toplam enerji tüketimi, https://cevreselgostergeler.csb.gov.tr/sektorlere-gore-toplam-enerji-tuketimi-i-85800 
Enerji Verimliliği Derneği. Enerji Verimliliği Bilinç Endeksi Kantitatif Araştırma Raporu 2020 http://www.enver.org.tr/media/catalog/pdf/enerji_verimliligi_bilinc_endeksi_kantitatif_raporu_2020. pdf

Erginer M., Cansız ÖF., Erginer İ. Trafik kaza sayısının ve yaralı sayısının yapay sinir ağları ile tahmini. Osmaniye Korkut Ata Üniversitesi Fen Bilimleri Enstitüsü Dergisi 2020; 3(1): 29-35.

Hamzaçebi C., Kutay F. Yapay sinir ağları ile Türkiye elektrik enerjisi tüketiminin 2010 yılına kadar tahmini. Gazi Üniversitesi Mühendislik Mimarlık Fakültesi Dergisi 2004; 19(3): 227-233.

Koray AKİ., Dirik AE. Derin öğrenme tabanlı ve PID kontrol tabanlı sürücüsüz araç sistemleri. Mühendislik Bilimleri ve Tasarım Dergisi 2020; 8(5): 306-316.

Mucuk M., Uysal D. Türkiye ekonomisinde enerji tüketimi ve ekonomik büyüme. Maliye Dergisi 2009; 157(1): 105-115.

Öztürk K., Şahin ME. Yapay Sinir ağları ve yapay zekâ'ya genel bir bakış. Takvim-i Vekayî 2018; 6(2): 25-36.

Soruşbay C. Karayolu ulaşımından kaynaklanan karbondioksit emisyonlarının çevreye etkisi ve kontrolü. Mühendis ve Makine 2007; 48(564): 22-26.

TÜIKK. Motorlu kara taşıtları istatistikleri https://www.tuik.gov.tr/ 